\title{
Tax compliance and information provision - A field experiment with small firms
}

\author{
Philipp Doerrenberg ${ }^{1,2,3 *}$, Jan Schmitz ${ }^{4}$
}

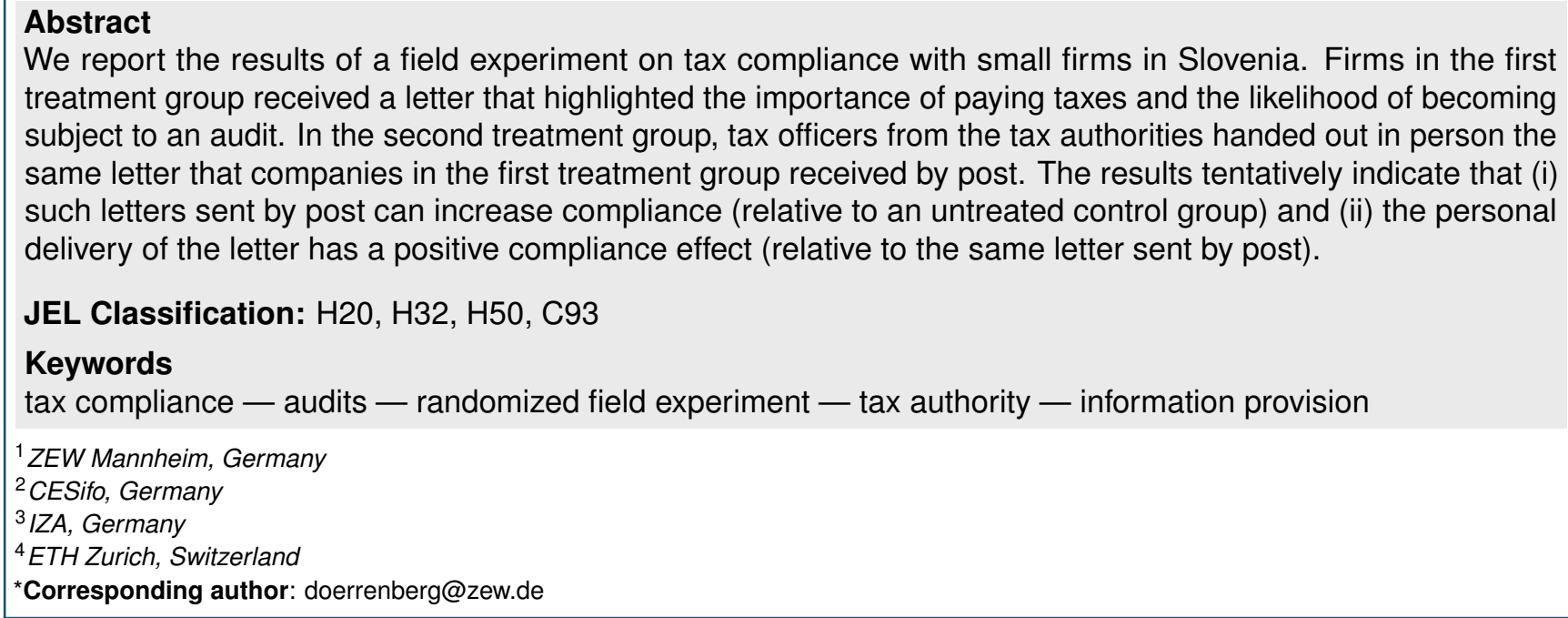

\section{Introduction}

We study tax compliance of small self-reporting firms -a group of taxpayers that is usually considered to have high propensities of noncompliance while yet being scarcely investigated in the literature- and explore how tax compliance responses differ between situations where information by the tax authorities are provided by letter or in person ${ }^{1}$.

We analyze a field experiment that was conducted in cooperation with the Slovenian tax authorities in January 2014. Taking into account the requests and capacities of the tax authorities, we were able to randomly assign 142 small accounting companies in a municipal region of Slovenia to an untreated control group and two treatment groups. Using official tax-reporting data provided by the Slovenian authorities, we study (i) how a letter containing moral appeals and salient audit probabilities affects tax compliance of small firms (Treatment I), and (ii) whether it makes a difference if the information in this letter are provided in personal interaction with the tax authority (Treatment II) ${ }^{2}$.

\footnotetext{
${ }^{1}$ Tax noncompliance is a significant problem in many countries around the world. For example, the Internal Revenue Service estimated the tax gap in the United States in 2006 to be around 450 billion US Dollars which is roughly $17 \%$ of all true tax liabilities (IRS 2012). Tax noncompliance is suggested to be an even more severe problem in developing and transitional countries (Schneider and Enste 2000, Loayza and Rigolini 2006). In addition, there is compelling evidence that a large portion of overall noncompliance can be attributed to taxpayers that self-report taxable income rather than those that are subject to third-party reporting and tax-withholding (Slemrod 2007, Kleven et al. 2011).

${ }^{2}$ In the second treatment group, the same letter, that was sent to firms in
}

Our results tentatively suggest that the treatment letter increases compliance, and leads to even more compliance if handed over in person. That is, changes in taxable earnings between 2012 and 2013 are higher in the first treatment group (letter sent by post) relative to the control group, and higher in the second treatment group (letter handed over in person) relative to the first treatment group. These effects are fairly sizable. For example, the average percentage change between the self-reported tax base in 2012 and 2013 is $1.87 \%$ in the control group, $12.63 \%$ in the "letter" treatment group and $20.28 \%$ in the "visit" treatment group.

Our analysis reveals that these differences across the groups are not distinguishable from zero in a statistical sense ${ }^{3}$. However, in the spirit of McCloskey and Ziliak (1996) and Ziliak and McCloskey (2004), we focus on the sign of the interventions, and provide suggestive evidence that the experimental treatments had effects on compliance. In addition, our findings are in line with the predictions that we derive to rationalize the experiment, and they correspond with the results of a recent -and independently conducted- field experiment in Latin America (Ortega and Scartascini 2015; see below), suggesting that the observed differences between groups may be due to the experimental intervention rather than pure chance.

Our paper speaks to the behavioral-economics literature

the first treatment group, was delivered in person to company representatives by members of so-called mobile units. See Section for details.

${ }^{3}$ The lack of statistical power is likely to be due to the low number of observations. Although initially planned, it was unfortunately not feasible to obtain more observations (which would have generated more statistical power). 
showing that personal communication may trigger stronger effects than less personal and more anonymous ways of communicating. For example, Ben-Ner and Putterman (2009) highlight that personal communication, compared to anonymous communication, increases trust in social dilemmas (see also Balliet 2009 for a review). In addition, we impose 'social pressure' on the firms by transmitting the message in person; this has been shown to have an effect in other contexts (e.g. DellaVigna et al. 2012).

Our experiment also contributes to the recently growing literature using field experiments to study tax compliance (e.g., Slemrod et al. 2001, Kleven et al. 2011, Fellner et al. 2013, Del Carpio 2014, Hallsworth et al. 2014, and Dwenger et al. 2015). Most of these field experiments study tax compliance of individuals and they use letters to transmit the treatment interventions. In light of these two strands of literature, our main contributions are to explore (i) whether some of the results of behavioral economics translate to tax-compliance behavior, (ii) whether small firms' compliance is responsive to behavioral interventions, and (iii) whether letters have similar compliance effects than other ways of transmitting the interventions to the taxpayers.

The only other paper to study the effects of different transmission channels in the context of tax compliance is Ortega and Scartascini (2015), which provides evidence from Colombia that personal visits have a larger effect than letters on the payment of tax liabilities among a sample of taxpayers with due tax payments. We complement this paper in that we study the effect of delivery method on reported taxable earnings of firms rather than on payment of outstanding liabilities of taxpayers with unpaid tax payments. This is particularly relevant because taxpayers with outstanding taxes might be substantially different from taxpayers without liabilities. In that regard, our findings suggest that personal communication may be a valuable tool to improve compliance also in a more general context.

The findings from our experiment are particularly important for tax authorities in countries with low cost of labor, i.e., where the personal contact with taxpayers is relatively cheap. The benefits of our experiment (through increased tax revenues) were 23 times higher than their cost (see section for a detailed cost-benefit analysis). Hence, developing countries, where tax evasion is suspected to be a particular problem (Schneider and Enste 2000, Loayza and Rigolini 2006) and labor costs are low, can particularly benefit from our findings.

\section{The field experiment}

\section{Experimental design}

142 small accounting firms in the Slovenian region of Kranj were chosen to be part of the field experiment. The companies did not know that they were subject to a randomized intervention. All participating firms were randomly assigned to be either in a control group, a "letter" treatment or a "visit" treatment. In total, 32 firms were selected to be in the control group, 80 firms were in the letter treatment and received a letter from the tax authorities, and 30 firms were randomly selected into the visit treatment which received a visit from the customs officers. Although we presume that official letters from the authorities are usually read, it is unobservable whether letters are really read and, if so, by whom. Thus, we increased the number of firms that received a letter to make meaningful inferences from our between-treatment comparisons. All experimental interventions took place between January 13th and January 22nd, 2014.

Firms in the control group were not treated in any way. Firms in the letter treatment received a letter by the local tax authority by post. The translated letter is displayed in the Appendix. The letter first included a reminder that paying taxes is "a civic duty" and that "taxes are important to maintain public schools, public infrastructure and public health provision". In a next step, the firms were informed that they are part of a special investigation which implies that $10 \%$ of all accounting firms in their region would be subject to tax audits. The letter also contained the information that these audits will be regarding the tax returns for the year 2013 which are due in April 2014 (hence after the treatment intervention) ${ }^{4}$. The general structure and wording of the letter is in line with field experiments in the literature (e.g., Kleven et al. 2011).

Firms in the visit treatment were personally approached and visited by so-called mobile units. These mobile units are an enforcement tool that the Slovenian tax authorities frequently use. Mobile units are staffed with rather low-skilled employees of the tax authorities who did not have any information about the details of the experiment. The tax officers in the mobile units were the same for all included companies ${ }^{5}$. The mobile units were instructed to ask for the highest company representative available and to hand over a letter. This letter was the exact same letter that firms in the letter treatment received by post. The tax officers read the letter to the company representative but were instructed not to respond to any questions asking for additional information not contained in the letter. As a result, firms in the visit treatment were provided the same information as firms in the letter treatment, but the transmission channel was different: personal interaction rather than a letter sent by post.

\section{Data, outcome variable and summary statistics}

The outcome variable in our analyses is the tax base (before tax reliefs) which is based on self-reported earnings and losses of the firms. The tax base variable therefore constitutes the basis for the firm's taxable income, which is the parameter that the public finance literature focuses on (see e.g., Saez et al. 2012). We have access to data regarding the tax years 2012 and 2013. Tax returns for each year are due in April of the following year. Because our interventions took place in January 2014, we have data on the reported tax bases of each

\footnotetext{
${ }^{4}$ The last paragraph further informed the companies that a few selected taxpayers who are clients of accounting companies in Kranj are being selected for audits as well.

5 The members of the mobile units are not in charge of performing any audits. This prevents any risks of bribery.
} 
firm before the treatment intervention and after the treatment intervention. In order to ensure credibility and avoid deception, the tax authorities audited the 2013 tax returns (due in April 2014) of 14 firms, corresponding closely to the audit probability of $10 \%$ that was stated in the treatment letters.

Table 1 presents summary statistics (mean, median and standard deviation) separated by control and treatment groups for the pre-treatment year 2012. We were provided information on profits, number of employees, number of branches of a firm and the tax base of all 142 accounting firms that were part of the experiment. The comparison of variables between treatment groups indicates that the treatment group means are relatively balanced in terms of the tax base (this is important because this is our dependent variable), the number of employees and the number of branches. The randomization process was such that pre-experiment mean profits appear considerably higher in the letter group than in the two other groups. However, non-parametric Mann-Whitney-U tests suggest that any differences (including profits) across groups are not statistically significant ${ }^{6}$.

Table 1. 2012 pre treatment: Summary by treatment

\begin{tabular}{lccccc}
\hline Group & Tax base & Profit & Employees & Branches & N \\
\hline Control & 9087.00 & 10628.93 & 2.81 & 1.22 & 32 \\
& 4038.29 & 5063.71 & 2 & 1 & \\
& $(11506.68)$ & $(12433.47)$ & $(2.84)$ & $(0.42)$ & \\
\hline Letter & 10650.31 & 14051.23 & 2.21 & 1.29 & 80 \\
& 1759.17 & 3790.42 & 2 & 1 & \\
& $(19615.78)$ & $(23905.72)$ & $(2.52)$ & $(0.53)$ & \\
\hline Visit & 10017.27 & 10824.84 & 2.03 & 1.43 & 30 \\
& 6083.435 & 7536.09 & 1 & 1 & \\
& $(12152.41)$ & $(12186.07)$ & $(2.25)$ & $(0.68)$ & \\
\hline Total & 10164.28 & 12598.38 & 2.31 & 1.30 & 142 \\
& 3118.19 & 4787.87 & 2 & 1 & \\
& $(16597.33)$ & $(19684.27)$ & $(2.54)$ & $(0.55)$ & \\
\hline
\end{tabular}

Notes: Summary statistics by treatment status before treatment in year 2012 Tax base is the firm's tax base (before reliefs) in that year (in EUR). Profit indicates profits made during the year (in EUR). Employees is the number of employees the firm has, and Branches is the number of the firm's branches. $N$ indicates the number of firms in each group. Reported are means and medians with standard deviations in parentheses. Firms in the control group were untreated. Firms in the first treatment group (Letter) received the treatment letter by post. Firms in the second treatment group (Visit) were handed over the treatment letter in person.

\section{Implementation of the experiment}

The field experiment was organized in cooperation with the tax authorities in Slovenia. We, the authors of this paper, designed the experiment taking into account the constraints (e.g., capability to run a certain number of audits), possibilities (e.g., availability of mobile units) and requests (e.g., the authorities

\footnotetext{
${ }^{6}$ P-values for control vs. letter, control vs. visit and visit vs. letter, respectively, for the different variables are: Tax Base: $0.30,0.59,0.12$; Profits: $0.57,0.61,0.25$; No of employees: $0.46,0.37,0.57$; Number of branches: $0.66,0.24,0.32$. Note that there are larger quantitative differences in median values between the treatment groups. However, differences are not statistically significant and we do not find that firms of different sizes are differently affected by our treatment intervention.
}

were interested in the effect of the mobile units that they implemented independently of and before the cooperation with us researchers) of the tax authority ${ }^{7}$. We authors randomized the firms into three groups (without any stratification), formulated the treatment letter and provided instructions on the implementation of the experiment. The actual implementation of the experiment was carried out by the Slovenian tax authority. That is, they, for example, sent the letters to the firms and organized the work of the mobile units. The tax authority also provided the tax return data that we use for empirical analyses.

\section{Predictions}

Effect of the letter treatment relative to control group The treatment letter can trigger compliance responses through three different channels. First, it contains a morale appeal which reminds taxpayers that taxes are a civic duty and that taxes are important to maintain public services and infrastructures. While some early papers have not found any effects of such morale appeals (e.g., Blumenthal et al. 2001 and Torgler 2004), recent field-experimental evidence by Hallsworth et al. (2014) and Del Carpio (2014) shows that moral appeals disclosed in letters to taxpayers have a positive effect on compliance. This induces us to hypothesize that the morale appeal in our set up either has a zero or a positive effect on compliance.

Second, it includes information about an audit probability of $10 \%$. This probability may be lower or higher than the perception about audit probabilities that firms had before they received the letter. Unfortunately, we do not have any information about the firms' priors about audit probabilities. The Slovenian authorities speculate that the perceived audit probability among small firms in this region of Slovenia is likely to be smaller than $10 \%$. Following the simple "rational" calculus of the seminal Allingham and Sandmo (1972) framework, this would suggest that the stated audit probability of $10 \%$ constitutes a positive shock in audit probability and therefore could have a positive effect on compliance. In addition, stating an audit probabilities informs taxpayers about the mere fact that audits are possible and it may increase the salience of audits. This could imply that the treatment letter increases compliance, even if the perceived audit probability had not been affected by the letters (Chetty et al. 2013, Paetzold and Winner 2014).

Third, the mere fact that the firms receive a treatment letter from the tax authorities could affect compliance. This might be for two reasons: On the one hand, communication and improved interaction between the tax authority and the taxpayers may affect trust towards the authorities ${ }^{8}$, suggesting

\footnotetext{
${ }^{7}$ We initially planned to extend the experiment to other municipal regions to obtain more observations, and eventually more statistical power. However, this was politically not feasible after the conduction of the initial experiment presented here.

${ }^{8}$ For example, the behavioral literature on communication finds that communication increases trust in situations of social dilemmas Balliet (2009), Ben-
} 
that compliance increases in response to communication and interaction between the tax authorities and the taxpayer. In the context of tax compliance, a few studies have stressed that an improved interaction of tax authority and taxpayer, for example in the form of better service quality of the tax authorities, may also have a positive effect on compliance (Alm et al. 2010, Alm 2012, Gangl et al. 2015). On the other hand, receiving a letter from the tax authorities might affect compliance for another reason: the letter may exert social pressure and which may increase compliance ${ }^{9}$.

All three mechanisms point in the direction that the letter may have a positive effect on compliance. While our experiment cannot help to disentangle which of the mechanisms is most prevalent, we can yet derive Prediction 1:

Prediction 1: The treatment letter sent by post increases tax compliance in the letter treatment relative to the control group.

\section{Effect of the visit treatment relative to the letter treat- ment}

Relative to the letter treatment, the personal delivery of the treatment letter did not change the level of information or any factors that would be relevant in a simple Allingham-Sandmo framework. However, there are at least three factors why taxpayers might respond differently to the visit than to the letter. First, the visit is a very costly signal (particularly more costly than the letter sent by post) of the tax authority towards the taxpayer. This signal might induce taxpayers to believe that they are under tight investigation. Firms may be under the impression that the tax authorities will only visit taxpayers which they suspect to be potential evaders -despite the actual audit probabilities that are equal in both treatments.

DellaVigna et al. (2012) highlight in the context of a charitable-giving that the effects of social pressure are higher in the presence of personal contact. Thus, taxpayers may increase compliance in response to the personal visit.

Second, the behavioral literature shows that face-to-face communication may trigger different outcomes than more anonymous ways of communication. For example, Ben-Ner and Putterman (2009) show that cooperation is higher in the presence of face-to-face interactions relative to anonymous interaction. They propose that the lack of anonymity and the emergence of personal ties could be the drivers of this result. Applied to our context, this implies that transmitting information face-to-face may be more effective in improving compliance than the rather anonymous letter.

\footnotetext{
Ner et al. (2011), Brandts et al. (2015), Charness and Dufwenberg (2006), Charness and Dufwenberg (2010) and triggers higher voluntary contributions in public good games (Isaac and Walker 1988, Ostrom et al. 1992, Brosig et al. 2003)

${ }^{9}$ For example, Funk (2010) shows, in a natural field experiment in Switzerland, that voter turnout significantly dropped when the government allowed the possibility to vote by mail. The reason that citizens felt less obliged to vote is that social pressure of fulfilling a civic duty was removed through the reform: before the reform it was easily observable for everybody to see if someone went to vote, especially in small communities.
}

Third, a more mechanical channel relates to the fact we cannot observe if all treatment letters are indeed read. While we believe that official letters from the tax authorities are usually taken seriously, we do not know with certainty. In contrast, we can be certain that the mobile-unit treatment was really received by the firms. As a result, our estimated letter effect only measures the effect of an intention to treat the firms (ITT), whereas the mobile-unit effect comes close to an actual treatment effect (TOT).

While it is again not possible to disentangle which of the mechanisms has a larger effect, they all point in the same direction and allow us to derive Prediction 2:

Prediction 2: The personal delivery of the treatment letter increases tax compliance in the visit treatment relative to the letter treatment.

\section{Results}

\section{Main Results}

Figure 1 depicts the mean tax bases in each treatment group in the years 2012 and 2013 and Figure 2 displays the relative average changes in tax base levels between the years 2012 and 2013. The figures indicate that the average increase in tax bases between the years 2012 and 2013, i.e., before and after the treatment intervention, was greater in the treatment groups relative to the control group. In addition, the average tax base increased by more in the visit treatment than in the letter treatment. The effects are quite sizable: while the average tax base almost did not grow in the control group (change: $1.87 \%$ ), it increased by $12.63 \%$ in the letter treatment and $20.28 \%$ in the visit treatment. However, non-parametric MannWhitney-U tests reveal that the differences between groups are not statistically significant (pairwise p-values for differences between groups in the 2013 (post-experiment) tax base are: Control vs Letter: 0.52; Control vs Visit: 0.43; Letter vs Visit: $0.13)$.

For a multivariate analysis, we estimate a simple DiD regression model (using OLS regressions with standard errors clustered on the firm level). The dependent variable is the tax base that is reported for tax purposes. The variables of interest are the interactions between the treatment group indicators and the indicator for the post-treatment year 2013 (see Appendix for details on the DiD regressions). Table 2 depicts the results from this regression model. The average tax bases in both treatment groups increased by more than the average tax base in the control group. The DiD coefficients in model (I) (without control variables) are 1175 and 1861 for treatment groups 1 and 2, respectively. The results therefore confirm that the treatment letter increases average compliance, and that this effect is even stronger if the letter is delivered in person rather than sent by post ${ }^{10}$. The coefficients are, however,

\footnotetext{
${ }^{10}$ Note that the coefficients perfectly mirror the descriptive statistics (see, for example, figure 1) as these coefficients can also be calculated as the plain
} 
Figure 1. Tax bases by Treatment Group, 2012 and 2013

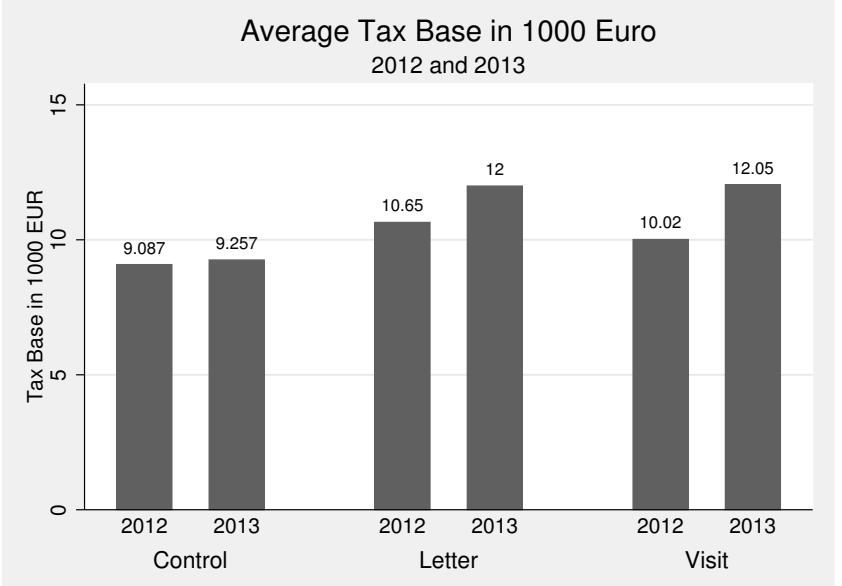

Notes: Displayed are the means of tax base (in 1000 EUR) by treatment group in 2012 and 2013 (before and after treatment interventions). $N=142$. Firms in the control group were untreated. Firms in the letter treatment received the treatment letter by post. Firms in visit group were handed over the treatment letter in person.

Figure 2. Tax bases changes by Treatment Group, 2013 vs 2012

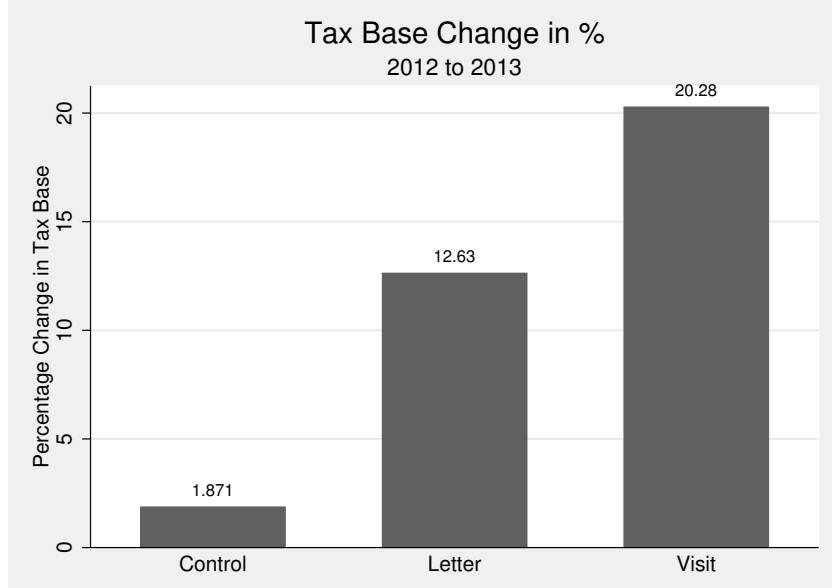

Notes: Displayed are the average relative changes in tax base between years 2012 and 2013 (before and after treatment interventions) by treatment group. $N=142$. Firms in the control group were untreated. Firms in the letter treatment received the treatment letter by post. Firms in the visit treatment were handed over the treatment letter in person.

not statistically significant, and we are not able to reject the null hypothesis of no treatment effect. Both the coefficient and the level of significance remain unchanged when we add control variables to the regression specification (see model (II) in table 2$)^{11}$.

differences in differences: $(12.00-10.65)-(9.257-9.087)=1.18$ for the letter treatment and $(12.05-10.02)-(9.257-9.087)=1.86$ for the visit treatment (all numbers in 1000 EUR).

${ }^{11}$ We also test if receiving any treatment (that is, we pool the treatment groups and test against the control group) has an effect relative to the control group. The corresponding regression results are displayed in Table 3. While Mann-Whitney tests for differences between groups are not significant, withingroup tests (signrank) suggest that the difference between 2012 and 2013 tax bases is statistically different for firms that either received a letter or visit, but
Table 2. DiD Regressions: Effects of treatments on tax base

\begin{tabular}{lcc}
\hline & $(\mathrm{I})$ & $(\mathrm{II})$ \\
\hline \multicolumn{2}{l}{ Reference group: Control } & \\
Letter $\times 2013$ & 1175.239 & 1175.239 \\
& $(2003.513)$ & $(2010.759)$ \\
Visit $\times 2013$ & 1861.440 & 1861.440 \\
& $(2207.443)$ & $(2215.427)$ \\
Letter Treat & 1563.302 & 3417.208 \\
& $(2996.443)$ & $(2757.402)$ \\
Visit Treat & 930.263 & 3358.661 \\
& $(2997.982)$ & $(3289.533)$ \\
Treat Year 2013 & 170.030 & 170.030 \\
& $(1344.378)$ & $(1349.240)$ \\
employees & & $3070.735^{* * *}$ \\
& & $(503.532)$ \\
branches & & -166.763 \\
& & $(2120.598)$ \\
constant & $9087.007^{* * *}$ & 653.808 \\
& $(2027.152)$ & $(3360.892)$ \\
\hline $\mathrm{N}$ & 284 & 284 \\
R2 & 0.004 & 0.221 \\
\hline
\end{tabular}

Notes: Difference-in-differences regressions. Standard errors in parentheses clustered on the firm level. Estimates are based on a sample of 142 firms and two periods (years 2012 and 2013). Significant levels are $*<0.10, * *$ $<0.05, * * *<0.01$. Dependent variable: Tax base (in EUR). Independent variables of interest are the interactions of the treatment-group indicators with the post-treatment-year dummy. Coefficients of interest are relative to the omitted control group. Firms in the letter treatment received a treatment letter by post. Firms in visit treatment were handed over the same treatment letter in person. Year 2013 observations are post treatment. Specification (II) includes control variables for number of employees and number of branches.

\section{Cost-benefit analysis of the experiment}

To the extent that the estimates are caused by the experimental interventions (rather than pure chance), we are able to use our results to calculate the net benefit of the experiment. For this purpose, the Slovenian tax authorities provided information on the costs of the experiment. As labor is relatively cheap in Slovenia, the mobile units generated total costs of $945.92 \mathrm{EUR}$, this includes salaries as well as expenses of the members of the mobile units. The costs for the postal letters are calculated to be 1.00 EUR per letter, which includes postage and labor costs for preparing the letters. In total, the letters cost 80 EUR, and the overall costs of the experiment are $945.92+80=1025.92$ EUR. The 14 audits that were conducted would have been conducted anyway, and therefore do not present extra costs of the experiment. Back-of-the-envelope calculations also allow us to calculate how much extra tax revenue was generated through the experiment. Using the rise in tax base in the control group as the counterfactual, our DiD-estimates indicate that the experiment generated an average increase in the tax base of 1175.24 EUR in the letter group and 1861.44

not for firms in the control group (p-values: 0.55 in Control group and 0.05 in Pooled Treatment group). 
Table 3. DiD Regressions: Effects of pooled treatment on tax base

\begin{tabular}{lcc}
\hline & $(\mathrm{I})$ & $(\mathrm{II})$ \\
\hline Reference group: Control & & \\
Treatments Pooled & 1390.655 & 3397.656 \\
& $(2645.396)$ & $(2533.899)$ \\
Treat Year 2013 & 170.030 & 170.030 \\
& $(1339.568)$ & $(1344.378)$ \\
Treat Pooled $\times 2013$ & 1362.384 & 1362.384 \\
& $(1783.406)$ & $(1789.809)$ \\
employees & & $3068.986^{* * *}$ \\
& & $(500.172)$ \\
branches & & -144.187 \\
& & $(2074.394)$ \\
constant & $9087.008^{* * *}$ & 631.212 \\
& $(2019.899)$ & $(3313.157)$ \\
\hline $\mathrm{N}$ R2 & 284 & 284 \\
& 0.004 & 0.221 \\
\hline
\end{tabular}

Notes: Difference-in-differences regressions. Standard errors in parentheses clustered on the firm level. Estimates are based on a sample of 142 firms and two periods (years 2012 and 2013). Significant levels are $*<0.10, * *$ $<0.05, * * *<0.01$. Pooled Treatments. Firms in the 'Treatments Pooled' group received a treatment letter by post or were handed over the same treatment letter in person. Dependent variable: Tax base (in EUR). Independent variables of interest are the interactions of the pooled-treatment-group indicator with the post-treatment-year dummy. Coefficients of interest are relative to the omitted control group. Year 2013 observations are post treatment. Specification (II) includes control variables for number of employees and number of branches.

EUR in the mobile-unit group. Considering that we had 80 firms in the letter treatment and 30 firms in the mobile-unit treatment, and that the applying tax rates for the firms was $17 \%$ in 2013, we calculate the gain from the experiment to be: $0.17 \times(80 \times 1175.24+30 \times 1861.44)=25,476.61$ EUR. This simple calculation then suggests that the net profit of the experiment was $25,476.61-1025.92=24,450.69$ EUR, which is more than 23 times as large as its costs.

\section{Discussion and concluding remarks}

We study a randomized field experiment on tax compliance conducted in cooperation with the Slovenian tax authorities. The experiment focuses on small accounting firms -a group of taxpayers that self-reports taxable income and potentially has high propensities to be noncompliant with tax laws. Our findings suggest that a treatment letter, which reminds the firms of the civic duty to pay taxes and informs about an audit probability of $10 \%$, may increase tax compliance. This effect is presumably even larger if this letter is handed over to the firms in person.

While not statistically significant, our results are in line with the theoretical predictions that we derive to rationalize the mechanisms behind our effects. Informed by different fields of literature, we elaborate that there are several channels that suggest that the letter (relative to control group) and the personal visit (relative to letter group) may have positive effects on compliance. In addition, the results are also in line with accompanying empirical evidence by Ortega and Scartascini $(2015)^{12}$. In light of the fact that the results can be rationalized theoretically and correspond with other empirical studies, we make the claim that the experimental results lack from the low number of observations rather than being evidence of null effects ${ }^{13}$.

It was one of the main aims of this paper to investigate whether an augmented form of transmitting information to taxpayers affects compliance. While it would have been desirable to disentangle the potential mechanisms through which the communication effect works, it may already be valuable information for tax authorities and policy makers that more personal contact can help to combat evasion -even without knowing why exactly the intervention works. Following an argument put forward by Chetty (2015), it may not be necessary from a policy perspective to disentangle the mechanisms at work. A policy maker can benefit from the mere fact that our treatments may have an impact on compliance, even without knowing why exactly these interventions have the desired effect. That is, providing first suggestive evidence that more personal interaction may work, can help tax authorities to improve compliance. This finding is especially interesting for tax authorities in countries where the costs of labor are relatively cheap, as in Slovenia, and where personal transmission of messages is likely to trigger extra revenue. Assuming that our estimates are indeed caused by the experimental interventions, a cost-benefit calculation (see Section ) shows that the positive revenue effects (from higher compliance) by far exceed the costs of the experiment.

\section{Acknowledgments}

We thank the editor, the associate editor and an anonymous referee for very helpful comments. Denvil Duncan, Jonas Fooken, Clemens Fuest, Tuomas Kosonen, Andreas Lange, Andreas Peichl, Christian Traxler, Christian Zehnder and Christopher Zeppenfeld provided helpful comments and suggestions on previous versions of the paper. We would like to thank the tax authorities in Slovenia, especially Jana Ǎchin amd Daria Šinkovec, for giving us the opportunity to design and organize the field experiment. Our contact to the Slovenian tax authorities was established at a workshop at the European Commission in 2013. We thank Thomas Hemmelgarn and Benedikt Herrmann for initiating this workshop and inviting us.

\footnotetext{
12 The results of the visit treatment also support the notion put forward by Alm (2012) (also see Alm et al. 2010 and Gangl et al. 2015) that an improved and more personal way of interaction between taxpayers and tax-authorities may improve compliance.

${ }^{13}$ It would certainly be desirable, though currently not politically feasible, to collect additional field-experimental observations. For example, a power analysis (with a significance level of 0.1 and test-power of 0.8 ) suggests that we would have required 195 observations per group to detect a statistically significant difference between the observed means of the control group and visit treatment group.
} 


\section{References}

Allingham, M. G. and A. Sandmo (1972). Income tax evasion: A theoretical analysis. Journal of Public Economics 1(3-4), 323 - 338.

Alm, J. (2012). Measuring, explaining, and controlling tax evasion: lessons from theory, experiments, and field studies. International Tax and Public Finance 19(1), 54-77.

Alm, J., T. Cherry, M. Jones, and M. McKee (2010). Taxpayer information assistance services and tax compliance behavior. Journal of Economic Psychology 31(4), 577-586.

Balliet, D. (2009). Communication and cooperation in social dilemmas: A meta-analytic review. Journal of Conflict Resolution.

Ben-Ner, A. and L. Putterman (2009). Trust, communication and contracts: An experiment. Journal of Economic Behavior \& Organization 70(1), 106-121.

Ben-Ner, A., L. Putterman, and T. Ren (2011). Lavish returns on cheap talk: Two-way communication in trust games. The Journal of Socio-Economics 40(1), 1-13.

Blumenthal, M., C. Christian, and J. Slemrod (2001). Do normative appeals affect tax compliance? evidence from a controlled experiment in minnesota. National Tax Journal 54(1), 125-138.

Brandts, J., M. Ellman, and G. Charness (2015). Let's talk: How communication affects contract design. Journal of the European Economic Association.

Brosig, J., J. Weimann, and A. Ockenfels (2003). The effect of communication media on cooperation. German Economic Review 4(2), 217-241.

Charness, G. and M. Dufwenberg (2006). Promises and partnership. Econometrica 74(6), 1579-1601.

Charness, G. and M. Dufwenberg (2010). Bare promises: An experiment. Economics Letters 107(2), 281-283.

Chetty, R. (2015). Behavioral economics and public policy: A pragmatic perspective. American Economic Review Papers and Proceedings forthcoming.

Chetty, R., J. N. Friedman, and E. Saez (2013). Using differences in knowledge across neighborhoods to uncover the impacts of the EITC on earnings. American Economic Review 103(7), 2683-2721.

Del Carpio, L. (2014). Are the neighbors cheating? Evidence from a social norm experiment on property taxes in Peru. mimeo.

DellaVigna, S., J. A. List, and U. Malmendier (2012). Testing for altruism and social pressure in charitable giving. The Quarterly Journal of Economics 127(1), 1-56.
Dwenger, N., H. Kleven, I. Rasul, and J. Rincke (2015). Extrinsic and intrinsic motivations for tax compliance: Evidence from a field experiment in Germany. American Economic Journal: Economic Policy. Forthcoming.

Fellner, G., R. Sausgruber, and C. Traxler (2013). Testing enforcement strategies in the field: Threat, moral appeal and social information. Journal of the European Economic Association 11(3), 634-660.

Funk, P. (2010). Social incentives and voter turnout: evidence from the swiss mail ballot system. Journal of the European Economic Association 8(5), 1077-1103.

Gangl, K., E. Hofmann, and E. Kirchler (2015). Tax authorities' interaction with taxpayers: A conception of compliance in social dilemmas by power and trust. New Ideas in Psychology 37(0), 13-23.

Hallsworth, M., J. A. List, R. D. Metcalfe, and I. Vlaev (2014). The behavioralist as tax collector: Using natural field experiments to enhance tax compliance. National Bureau of Economic Research (NBER) Working Paper 20007.

IRS (2012). Tax gap for tax year 2006. United States Internal Revenue Service. Available online: http://www.irs.gov/pub/newsroom/overview_tax_gap_2006.pdf (accessed June 2014).

Isaac, R. M. and J. M. Walker (1988). Communication and free-riding behavior: The voluntary contribution mechanism. Economic Inquiry 26(4), 585-608.

Kleven, H. J., M. B. Knudsen, C. T. Kreiner, S. Pedersen, and E. Saez (2011). Unwilling or unable to cheat? Evidence from a tax audit experiment in Denmark. Econometrica 79(3), 651-692.

Loayza, N. V. and J. Rigolini (2006). Informality trends and cycles. World bank policy research working paper 4078.

McCloskey, D. N. and S. T. Ziliak (1996). The standard error of regressions. Journal of Economic Literature 34(1), 97-114.

Ortega, D. and C. Scartascini (2015). Don't blame the messenger: A field experiment on delivery methods for increasing tax compliance. Inter-American Development Bank WP 627.

Ostrom, E., J. Walker, and R. Gardner (1992). Covenants with and without a sword: Self-governance is possible. American Political Science Review 86(02), 404-417.

Paetzold, J. and H. Winner (2014). Unwilling, unable or uninformed to cheat. tax evasion via (quasi-) selfreporting in austria. Unpublished working paper.

Saez, E., J. Slemrod, and S. H. Giertz (2012). The elasticity of taxable income with respect to marginal tax rates: A critical review. Journal of Economic Literature 50(1), $3-50$. 
Schneider, F. and D. H. Enste (2000). Shadow economies: Size, causes, and consequences. Journal of Economic Literature 38(1), 77-114.

Slemrod, J. (2007). Cheating ourselves: The economics of tax evasion. Journal of Economic Perspectives 21(1), $25-48$.

Slemrod, J., M. Blumenthal, and C. Christian (2001). Taxpayer response to an increased probability of audit: evidence from a controlled experiment in minnesota. Journal of Public Economics 79(3), 455 - 483.

Torgler, B. (2004). Moral suasion: An alternative tax policy strategy? evidence from a controlled field experiment in switzerland. Economics of Governance 5(3), 235253.

Ziliak, S. T. and D. N. McCloskey (2004). Size matters: the standard error of regressions in the american economic review. The Journal of Socio-Economics 33(5), 527546. 